\title{
THE IMPACT OF COVID-19 ON THE SCHOOL WORLD
}

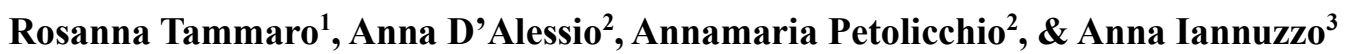 \\ ${ }^{I}$ Department of Human, Philosophic and Education Sciences (DISUFF), University of Salerno (Italy) \\ ${ }^{2}$ Salerno (Italy) \\ ${ }^{3}$ Avellino (Italy)
}

\begin{abstract}
The COVID-19 pandemic is firstly a health crisis, but also a huge shock for the educational world (from primary school to university). The impact of COVID-19 on the school world has been very strong. Education has been hit hard with schools closing down internationally and students forced to stay home. The global lockdown of schools has caused a severe and probably unparalleled disruption in student learning. In this scenario, teaching has moved online, the school world has suddenly been forced to move towards the dimension of distance learning, in Italian DAD. A new acronym, DAD, which is used to identify a type of training and teaching that is implemented, precisely, remotely or where there is no sharing of a space and a physical interaction between teacher and students, but everything is mediated by the use of technological means and the internet.

The article aims to describe to a teacher audience, the most important steps in online/distance learning, $\mathrm{DAD}$, adopted during pandemic in Italian school system, with its implications for teachers and students. After a brief overview of the main theoretical frameworks, we will try to describe the current state, in our country, of this methodology, its characteristics, its objectives and the roles of the actors involved. This article is an exploratory case study that involved the use of an observational research technique. It sought, through "living the situation in first person", to critically consider the advantages and disadvantages of this new didactic approach, of this different way of studying/teaching and the future prospects in restarting lessons in a Covid world.
\end{abstract}

Keywords: Distance learning, face-to-face learning, pandemic, digital technologies, COVID-19.

\section{Introduction}

The COVID-19 pandemic has changed education permanently. It has drastically forced the distinctive rise to e-learning, so that teaching is undertaken remotely and on digital platforms. A new acronym, DAD, distance learning, is often used in a generic way to identify a type of training and teaching that is implemented, precisely, remotely or where there is no sharing of a space and a physical interaction between teacher and students, but everything is mediated by the use of technological means and the internet.

The term online/e-learning is commonly used. Or perhaps it would be more accurate to say that it has become a "hot" word, used, sometimes abused, in educational areas. The difference at present is that every segment of the education sector must launch this method of teaching, which is therefore highlighting, on a large scale, its advantages and disadvantages. Online and traditional education, in presence, involve two different types of learning, each with its own teaching method, its own channels and guidelines. This asynchronous system allows students to attend classes, work, communicate, take exams, and access content wherever they are. Another aspect of distance learning is that it stimulates students' independence and curiosity, collaborative work, critical thinking, and self-directed learning. This system also diversifies sources of knowledge. With classroom learning, students go to a physical class where teaching takes place and much of the learning takes place. With this method, students take on a more passive role and adapt to the teacher's pace and teaching method. The teacher is the primary source of information.

Turning to the theories underlying distance education, we will start with the opening sentence in the 2003 Handbook of Distance Education states, "America's approach to distance education has been pragmatic and theoretical" (Saba, 2003, p. 3). In addition, Charles Wedemeyer, a theorist who has made notable contributions in the area of distance education theory, claims that distance education has yet "to develop a theory related to the mainstream of educational thought and practice" (Keegan, 1996, p. 56). As noted by Saba (2003), distance education's roots in the United States date back to the 1800's; however, the first scholarly journal, The American Journal of Distance Education, was not started until 1987, by 
Michael G. Moore. This journal History, Theory, and Quality of DE 15 and the symposia of the American Center for the Study of Distance Education, organized by Moore, emphasize the importance of distance education theory and recognize the contributions of research and practice in the discipline of distance education (Saba, 2003). Distance education theories, developed from leading scholars in the discipline, such as Holmberg, Wedemeyer, Moore and Peters, can be categorized into three broad groups (Keegan, 1996; Saba, 2003).

1. Theories of autonomy and independence. Borje Holmberg, Charles Wedemeyer, Rudolf Delling, and Michael G. Moore developed theories of distance education that placed the learner in the middle of the educational process (Keegan, 1996; Saba, 2003). According to Saba (2003), "the centrality of the learner is one of the distinguishing features of distance education, and understanding this fact is essential for discerning why it is essentially different from other forms of education" (p. 4).

2. Theory of industrialization. Otto Peters, Desmond Keegan, Randy Garrison, and John Anderson are theorists in distance education that have developed theories that are mainly interested in how the field functions and how it is organized. Structural concerns and issues (e.g. industrialization) are the main foci of this group of theories, along with how those issues influence the teaching and learning process (Keegan, 1996; Saba, 2003).

3. Theories of interaction and communication. Contemporary ideas and views of Holmberg, John A. Baath, Kevin C. Smith, David Stewart, and John S. Daniel History, Theory, and Quality of DE 16 highlight the constructs of interaction and communication as important factors in distance education (Keegan, 1996).

\section{Method}

\subsection{Face to face vs distance learning}

Traditional learning, Face-to-face, is essentially linear, it tries to follow a predetermined sequence of programmed and pre-ordered passages typical of lectures and textbook contents; it is centered on the knowledge achieved by each student and basically follows a single direction, which goes from the teacher to the learner. Traditional teaching sees the teacher "only" in front of the class and the transmission of the didactic content is linked to his knowledge and his ability to be understood and to arouse interest. It is characterized by the verticality of the communication, by the passivity of the addressees; the success of the lesson is directly based on the communication and teaching skills of the teacher; on the teaching model based on the idea of teaching as a "transfer of knowledge" from the teacher to the students; on the difficulty in differentiating the teaching contribution; on the tendency to favor verbal communication over other communication codes; excessive weight of the "class group" compared to other possible aggregations.

According to Ray Williams, a writer who contributes to Psychology Today, human interaction is fundamental to one's life and is one of the characteristics that distinguishes the human being (Harry, Keith, John Magnus, Keegan, Desmond, 1993).

Distance learning can adversely affect the quality of training provided, and virtual training creates a blanket of anonymity which allows students to participate in a misleading way. The school covers conditions of space, time and relationship, which can only be activated in presence. Space is of considerable importance for the learning process of students. They must be able to face each other and with teachers during the preparation of an activity; have the opportunity to work as a couple and in a small group; be able to move, work and relate in a shared space; have opportunities to meet and exchange with other mates of the school. The digital environment is a virtual place and it is therefore a different kind of learning environment from the classroom, which has its own physicality (Anna D'Alessio, 2019). Physical space, which was the specific and shared element of schooling, has been restricted to housing. Children and young people are located in very different environments and almost never suitable for learning. The public-school space enters the private space house, creating a hybrid element that involves disorientation.

The remote learning relationships have changed considerably: without bodies the relationship is only virtual. At school the educational model is based on the autonomy of the students, on self-study: it is a personal work in a collective path, shared with the classmates and checked before, during and after by the teacher, who notices the difficulties and intervenes, dealing directly with the student, supporting him, reassuring him. With distance learning all this is impossible: the student is alone (Moore, G. Michael, Kearsley, Greg, 1996).

2.1.1. Teachers and students' role within distance learning. In distance learning, the horizontal relationship among students, that is, among peers who activate questions, answers, initiatives, forms of mutual help and links that strengthen or prevent learning and make them significant on human level, is greatly reduced, but for this reason it must be treated with the utmost care. Within a virtual class students can share thoughts and images, jobs and opinions, but they cannot share the experience that a group of 
students make a class: smiles, eyes, quick interactions without the teachers' knowledge, the sandwich had together on break, the volleyball match are all possibilities of mutual knowledge and informal learning that in distance learning environment fail. However, efforts can be made to remedy this by planning activities that require exchange and collaboration between students, such as collective writing, debates, exchanges of messages to develop shared responses to problems that require a common effort. In any case, you should not give up having a class perspective.

The vertical educational relationship, since it provides a relationship between teachers and students, that is among adults, who possess expert knowledge, and learners, it is activate primarily by teachers and, as in presence - but with reduced possibilities for correction in itinere - must be calibrated according to the students, the contexts from which they come from, the difficulty of the content and the tools available. Proposing distance activities, therefore, we must consider the pedagogical profiles of students, their learning styles, their motivational drive, their knowledge, the tools they possess and their autonomy. In this sense, precisely because there is a lack of direct comparison in situation, distance learning requires greater attention in the planning phase and a strong sharing of basic choices (Andersen, S C, and H S Nielsen, 2019).

The context of distance learning is more rigid than that of teaching in presence. In addition, as mentioned above, the educational motivation of the group is changed, but the teacher can still act as a mediator. First of all, the teacher can present the contents in multidimensional form, in order to speak to the cognitive styles of all students, also he can calibrate the contents and fix time so that no one is left behind, finally he can continue to stimulate the relationship between peers and to make his human closeness felt with direct personal contacts. The aim of teaching should promote greater autonomy, and distance learning must be kept firm and declined according to the possibilities offered by the tools available (Anna D’Alessio,2014).

2.1.2. To convert a face to face class to online/remote learning. Our original and innovative learning experience. The 2020 will surely be remembered in the history manuals as a year of great social, relational, educational changes. Imagining a new secular dating, it could be considered as the year zero, the year of "non-return", which has seen a sudden transformation in economic, health, geopolitical, organizational terms. The school was overwhelmed by this tsunami and was catapulted into a dimension that, although long desired, was struggling to take off: distance learning. As Bonazza (2014) points out, the means that will be used cannot be conceived according to an exclusively instrumental function but must be considered "as constitutive elements of the end itself: it will therefore be necessary to proceed by identifying the values enclosed in the means, contemporary to their function" (p.229). The first obstacles we faced were of a practical nature: protection of privacy, primarily of learners; choice of the platform that could be closer to our educational needs. With regard to the first issue, the bounce of circulars and ministerial statements, often contradictory, initially led to autonomous choices within the class councils and then to arrive at a shared solution, with the consent of the parents, which provided for the use of the camera only during the written tests and interviews. It was difficult to choose, within the wide range of offers, the educational platform that would meet everyone's needs. In our daily pre-Covid practice, we used more than one platform, according to the disciplines and their purposes of use. Each had strengths and weaknesses, but it was necessary, both to facilitate our students and for the traceability of the routes, to adopt only one that could guarantee access through institutional accounts.

Once the practical problems were resolved, there have been basically three guidelines along which we have moved: ensuring fair conditions; redesigning educational interventions; remodulating of the assessment tests and the evaluation headings.

Even before proceeding with distance learning, it was necessary to control the instrumental equipment of the individual students, the possibilities of connection and the quality of the network. The school has tried to provide learners without the necessary equipment, but in some areas, especially inland, the lack of broadband network has partially frustrated the effort.

Speech aside deserves the re-design of educational and training interventions. It was immediately apparent that the objectives had to be recalibrated, certain new evidence of acceptability had to be recalibrated and teaching experiences rescheduled, in view of the different educational context. The contingent circumstance has made us more aware that the challenge is to make the transition from a highly centralized design on teaching, which anticipates and breaks down the process in an analytical way, corroborating the transfer of disciplinary content, to a design aimed at learning, which does not anticipate actions but adapts to processes and reflects the project, bending it on the training needs of the students. Distance learning involves a different methodological-didactic approach than the lesson in presence. In order to make educational intervention effective and efficient, it is necessary to promote the sharing and active participation of the learner. In view of the fact that the attention does not remain unchanged throughout the lesson, presenting an alternation between moments of increase and moments of decrease in the level of attention, video lessons with a maximum duration of 15/20 minutes were chosen. It was also necessary to make further choices regarding the content and based on the suggestions made by 
Wiggins and McTighe (2005). In their design proposal, Backward Design, the two U.S. authors identify four principles that can guide teachers in choosing content: transferability: centrality: involvement.

Great importance has been given to monitoring, both formally, through regular documents on the progress of activities, and informal, based on the exchange of views and information between teachers and learners.

"Referring to the monitoring of training in multimedia environments, Moretti (2005), taking up the distinction presented by Calvani \& Rotta (2000), distinguishes three types of monitoring: internal to the training system and transparent to some of the system's staff; reactive: the documentation and data provided by the surveys are used to modify, integrate or correct the paths or "to guide the movements adopted by some of the protagonists of the training path" (Moretti, 2005, p.235); dynamic: its main feature is to change together with the learning paths" (Petolicchio, 2019, p.143).

With regard to evaluation, we focused, as Galliani suggests (2015), on the three conditions that ensure alignment and consistency between the training process and the evaluation process: identify the aims of the training process; develop interactions between trainees and learning objects, manage the enactive dynamics that link content to cognitive and motivational strategies.

Great importance has been given to the training function of the evaluation, which, thanks to the continuous feedback received and sent to the students, has allowed not only to orient and remodulate the activities but, above all, to tend to individualized curricula, which allow each student to achieve the same cultural, and personalized skills, which offer the opportunity to discover the originality of the individual.

\section{Result}

What has the covid-19 crisis taught us about online teaching?

As the coronavirus spread, education institutions were obliged to face a major challenge: how could they continue to offer instruction if face to face classes and lectures were closed? An increasing number moved classes online as a short-term solution.

When the lesson is supported by technology, the expectations of the students change. A simple diffusion of modern technological equipment should not be considered but rather a support for innovation of the learning environment. In this context, the risk of " isolation" can be very high when considering that students are greatly attracted by the world of the media. Thus, the teacher must consider the emotional-affective factors of the educational relationship and should pay attention to the training as well as organization of the class, ie the way of working out the goals and the tasks, and of communicating student deliveries, predisposing the spaces, times, preparing and distributing materials, tests and evaluating processes and products.

Our personal teaching experience has shown that a new learning environment starting from the renewed classroom is powerful. Proper teaching methodology should be moved by the student. This will make learning meaningful to students, because it starts from their interests, their training needs, socio-cultural reality in which they live, thus maintaining high motivation level and the interest and reward the application. Students have changed and so have their development needs. The demand for education is very different from the past. It starts from understanding the students and responding to their needs.

Preparing for tomorrow. We must remember that, as the Chinese proverb says, spring always ends winter. It is important to establish a reference framework that helps decision-making processes in the higher education sector (Anna D'Alessio,2006), without forgetting that the first priority must be the protection of health; ensuring the right to education of all persons within a framework of equal opportunities and non-discrimination is the first priority; as well as promoting and supporting inclusive, relevant, adequate and quality programs and initiatives; leaving no student behind, the crisis has a different impact on different student profiles, but it is undeniable that it deepens existing inequalities and generates new ones. Prepare in time for the resumption of face-to-face classes, avoiding having to rush and offering, from the beginning, clarity in communication to the entire academic community and administrative and academic security, so that teachers, administrative and service personnel, and students can place themselves in the new context knowing in advance the provisions, processes and mechanisms designed to resume teaching activities.

\section{Discussion}

In the recent months the school has been at the centre of a debate that, never before, has everyone involved.

Suddenly the way of "schooling" has changed, the community dimension has been lost with its rituality. There is no doubt that one of the key elements of the learning process is the dynamic relationship shared among students, and between students and teachers. Face-to-face learning fosters these relationships; this dynamism can be minimized, or lost, when training is undertaken remotely or in 
virtual format. The wealth of information and experiences are deduced from body behaviour and language, gestures, tone and volume of voice. Face-to-face communication allows the whole experience not only to be heard, but also seen and felt. That shared "physical" space, considered by Gennari (1997) "pedagogical object", therefore usable in teaching, and "pedagogical subject", as an activator of autonomous training courses, has been missing. It is sad to see that it has taken a pandemic to put into practice what has long been planned on paper!

Vertecchi's thought (1999) is fully topical and fully acceptable, pointing out that there is still "great confusion about the role of the school in contemporary society. It is no longer clear what its task is, since the responsibility of the school in relation to cultural acquisitions appears to have diminished, while an increasing emphasis is placed on educational dimensions which, in most cases, are only an attempt to remove aspects of the discomfort of civil society. The contradictions of the latter are passed on to the school, with the sole effect of making the specificity of its role in the social context less and less recognizable" (p.145).

\section{Acknowledgements}

The views, thoughts, and opinions expressed in this article are solely those of the authors and not necessarily associated with the view of a specific research in education. They are only linked to an original and innovative learning experience. The authors' professional experience has been mainly focused on the teaching trying to turn lessons into an online version in a few weeks using a $100 \%$ online synchronous approach. This was an exploratory case study since the main purpose was to "live in first person the situation" to see if a well-structured online class is a powerful tool to facilitate the teaching /learning process in Times of Crisis.

\section{References}

Andersen, S C, \& H S Nielsen (2019). Learning from Performance Information, Journal of Public Administration Research and Theory.

Bonazza V. (2014). La dimensione assiologica: equità, rendicontazione, miglioramento. In L. Galliani, A.M. Notti (Ed). Valutazione educativa, 227-254. Lecce-Brescia: Pensa MultiMedia

Calvani A., Rotta M. (2000). Fare formazione in Internet. Manuale di didattica online. Trento: Erikson.

D’Alessio A. (2006), La progettazione didattica. In A.M.Notti, Il controllo dei processi didattici e gestionali. La scuola che si valuta. Pensa, Lecce.

D’Alessio A. (2014), La relazione educativa come esperienza reale del vasto e complesso mondo dei rapporti interpersonali, Quaderni dell'Istituto Superiore di Scienze Religiose Giovanni Duns Scoto.

D’Alessio A. (2019), Immersive didactic approach teaching with virtual reality as integrated learning environments, 11th International Conference on Education and New Learning Technologies.

Galliani L. (2015). Epistemologia della valutazione educativa. In L. Galliani (Ed). Agire valutativo: manuale per docenti e formatori, 25-39. Brescia: La Scuola.

Gennari M. (1997). Pedagogia degli ambienti educativi. Roma: Armando Editore.

Harry, Keith, John Magnus, Keegan, Desmond (1993) Distance Education: New Perspectives Routledge in London and New York.

Keegan, D (Ed.) (1996). Foundations of distance education (3rd ed.). London: Routledge.

Keegan, D. (1986). The foundations of distance education. London: Croom Helm.

Moore, G. Michael, Kearsley, Greg (1996) Distance Education System View. Wadsworth Publishing Company in United States of America.

Moretti G. (2005). Prove semistrutturate e valutazione negli ambienti multimediali per la formazione. In G. Domenici (Ed). Le prove semistrutturate di verifica degli apprendimenti, 228-246. Torino: UTET.

Petolicchio A. (2019). Progettare per competenze. La progettazione nella logica del Lifelong learning. Roma: Anicia.

Saba, F. (2003). Distance education theory, methodology, and epistemology: A pragmatic paradigm. In M.G. Moore \& W.G. Anderson (Eds.), Handbook of distance education, 3-20. Mahwah, NJ: Lawrence Erlbaum Associates

Vertecchi B. (1999). Cinque idee per la riforma. In A. Sasso, S. Toselli (Eds). La scuola nella società della conoscenza. Formazione, tecnologie, informazione, modelli di vita. Milano: Bruno Mondadori.

Wiggins G., McTighe J. (2005). Understanding by Design. Alexandria-Virginia (USA): ASCD, expanded 2nd edition. 